\title{
El parlamento catódico: los programas de debate sobre la actualidad política durante la transición (1976-1979)
}

Recibido: 04/02/2014

\author{
Virginia MARTÍN JIMÉNEZ \\ Universidad de Valladolid \\ virgimj@hmca.uva.es
}

Aceptado: 10/03/2014

\begin{abstract}
Resumen
En el contexto de transformación político-social que vivió España durante la década de los setenta, Televisión Española puso en marcha una serie de programas en los que los acontecimientos que jalonaron el cambio eran debatidos por políticos y especialistas. Este artículo analiza los espacios de debate sobre actualidad política que emitió la cadena estatal durante la Transición. Para ello se estudian los debates políticos que estuvieron en antena para posteriormente prestar atención a un caso concreto -España, hoydurante las semanas previas al primer gran hito de la Transición: el referéndum de la Ley para la Reforma Política. Tras ese análisis se concluye que TVE actuó como un pequeño parlamento en el que el enfoque y tratamiento de los temas políticos debatidos reflejaban el espíritu de consenso que guió el proyecto de Transición en sus inicios, a la par que socializaba en democracia a la audiencia.
\end{abstract}

Palabras clave: Transición democrática, debates, política, Televisión Española (TVE).

\section{Cathode parliament: current politics debates during transition (1976-1979)}

\begin{abstract}
In the context of socio-political changes that Spain lived during the seventies, Spanish Television started up several programs where the current that marked the change were discussed by political and specialists. This article analyzes the politics debate that state television issued during the Transition. First of all, this study aims to show the politics debates that were on the air and, afterwards, pays attention to an specific case -Spain, today (España, hoy)- during the weeks before the referendum on Political Reform Law. The article concludes that TVE played as an small parliament in which the approach and treatment of political issues socialized in democracy to the audience and reflected the consensus spirit that guided the Transition project.
\end{abstract}

Keywords: Democratic transition, debates,-politics, Spanish Television (TVE)

Referencia normalizada: MARTÍN JIMÉNEZ, Virginia (2014): "El parlamento catódico: los programas de debate sobre la actualidad política durante la Transición (1976-1979)". Estudios sobre el Mensaje Periodístico, Vol. 20, Núm. especial, pp. 121-137. Madrid, Servicio de Publicaciones de la Universidad Complutense.

Sumario: 1. Introducción: objeto de estudio y planteamiento de la investigación. 2. Contexto históricomediático: la televisión como agente de resocialización política. 3. Los debates de la Transición: clasificación y rasgos distintivos; 3.1 . Principales programas de debate político. 4. Haciendo política en televisión: España, hoy ante el referéndum de la Ley para la Reforma Política. 5. Conclusiones. 6. Referencias.

\section{Introducción: objeto de estudio y planteamiento de la investigación ${ }^{1}$}

Durante la segunda mitad de la década de los setenta, España va a vivir una profunda transformación en el ámbito político y social hasta convertirse en un estado demo-

1 Esta investigación se ha realizado dentro de las actividades del proyecto de investigación "Televisión y Cultura popular durante el franquismo: Programación, programas y consumo televisivo (1956-1975)", ref. HAR2011-27937. 
crático. En ese contexto histórico, la cadena pública Televisión Española fue acompañando el cambio estatal con la incorporación de nuevos programas a su parrilla. Entre estos espacios destacan especialmente los debates sobre actualidad política que se emitieron durante la Transición y en los que políticos y especialistas dialogaron acerca de los acontecimientos clave que fueron jalonando el cambio. La relevancia de la incorporación de estas novedades en la pequeña pantalla estriba en el hecho de que, concluida la dictadura franquista, la sociedad española tenía la posibilidad de consumir unos espacios televisivos en los que se ofrecía un contenido que convertía la política y las decisiones gubernamentales en algo debatible, quedando así legitimada la pluralidad de ideas y opiniones.

Debido al mensaje de cambio democrático que difundían estos programas y a las ideas políticas que en ellos se transmitían, este artículo analiza los espacios de debate sobre actualidad política que emitió la cadena estatal durante los inicios de la Transición. Para ello se busca, primero, caracterizar los programas de debates políticos que estuvieron en antena en ese período centrándose, principalmente, en sus atributos más destacados, estructura y rasgos innovadores; para, posteriormente, hacer un análisis más profundo de contenido de los debates que se emitieron con motivo del primer gran hito democratizador de la Transición en el que los ciudadanos jugaron un papel activo al tener que acudir a las urnas. Nos referimos a la Ley para la Reforma Política aprobada en referéndum en diciembre de 1976. Tras este estudio de la programación de debates políticos se concluye que TVE actuó como un pequeño parlamento en el que el enfoque y tratamiento de los temas políticos a debate reflejaban el espíritu de consenso que guiaba el proyecto de Transición a la par que socializaba en democracia a la audiencia.

Para la realización de esta investigación se empleó como fuente principal, tras una revisión bibliográfica, los fondos del archivo de TVE junto con los anuarios de RTVE, los contenidos sobre programación televisiva de publicaciones periódicas como Cuadernos para el diálogo y la revista Tele Radio. Durante la elaboración de este artículo, la relación de programas de debate y su posterior selección para el visionado se han determinado a partir de la búsqueda del clasificador de género "Debate" en la Base de Datos del Archivo de Televisión Española teniendo siempre en cuenta la delimitación cronológica de la Transición democrática.

\section{Contexto histórico-mediático: la televisión como agente de resocialización po- lítica}

La historiografía ha mostrado una tendencia a delimitar la Transición democrática española tomando como punto de partida el fallecimiento de Francisco Franco, 20 de noviembre de 1975, y ubicando el final en la victoria electoral del Partido Socialista (PSOE) el 28 de octubre de 1982 (Tusell, 1999). No obstante, aun considerando apropiado este criterio cronológico- y sin olvidar el empleado por otros autores (Juliá et al, 1996) (Morodo, 1993) (Prego, 1995) (Sartorius y Sabio, 2007)- este trabajo se estructura, principalmente, en torno a una primera etapa del cambio democrático, la del consenso (desde mediados de 1976 hasta finales de 1978), aunque también se tendrá en cuenta, para poder comprender mejor la evolución de los programas de debates, lo 
que podríamos denominar, dentro de la Transición, el período de pre-consenso, que iría de la muerte de Franco al nombramiento de Adolfo Suárez como presidente del Gobierno en 1976, y otro de post-consenso que se desarrollaría desde la entrada en vigor de la Constitución (diciembre de 1978) y hasta la victoria socialista en el 82.

Por consenso se entiende, en palabras de Miquel Roca, "la suma de muchas renuncias" (Juliá et al, 1996: 214); así pues, la etapa del consenso abarcaría los años de la Transición que discurrieron entre el nombramiento de Adolfo Suárez como presidente del Gobierno, julio de 1976, hasta la entrada en vigor de la Constitución. A finales de 1978, al contar el país con un marco legal democrático y estando a las puertas la nueva convocatoria electoral, las fuerzas políticas dieron por terminado el consenso, comenzando así las luchas intestinas por alcanzar el poder. Todo ello se reflejó en la programación televisiva, en la repercusión que ésta tuvo en otros medios de comunicación y en la actitud que tomaron los partidos políticos al respecto.

En ese modelo de Transición consensuada será decisivo el papel de los dirigentes políticos y, en consecuencia, el de los medios de comunicación con los que éstos contaban; muy especialmente los medios de carácter estatal como era Televisión Española. De ahí que el objeto de análisis principal de este artículo vayan a ser los debates de actualidad política que se emitieron en TVE durante los años de la Transición en los que el consenso se convirtió en el mecanismo que permitió la continuidad del proceso democratizador.

A lo largo de esta etapa histórica, al mismo tiempo que se perseguía la normalización en el ámbito político, fue también necesario llevar a cabo un proceso de socialización democrática de una población que había vivido durante varias décadas en un sistema dictatorial y ahora necesitaba comprender y poner en práctica las bases de la convivencia democrática (Benedicto, 1993: 645). En esta tarea de conformación de una nueva cultura cívico-política, la televisión, debido al amplio espectro de población que abarcaba su audiencia y aprovechando el monopolio del que disfrutaba durante los años de la Transición, pasó a ser uno de los principales agentes estatales de una resocialización que, al colaborar en que la democratización política trascurriera en paralelo a la democratización de la sociedad, se convertiría en la garantía del éxito final del cambio.

Una pieza clave de este proceso de aculturación lo encontramos en la puesta en marcha de un gran número de programas de debate donde se expresaban opiniones sobre los temas de actualidad que iban marcando la transformación democrática. Los contenidos -políticos, económicos y sociales- de estos espacios de debate, los invitados que a ellos acudían y la manera en la que afrontaban los temas de actualidad parecía que hubieran sido pensados por los dirigentes del medio para representar ante los telespectadores, durante los primeros años de la Transición, una especie de tipo ideal de parlamento democrático a pequeña escala, donde primaba el consenso y el diálogo, mientras que la confrontación, salvo en escasas ocasiones, apenas tenía lugar. Esa representación, como veremos en estas páginas, coincidía con la imagen que del gobierno de Adolfo Suárez quería ofrecer la televisión pública a los ciudadanos.

Teniendo esto en cuenta, este artículo parte de la premisa de que los debates televisivos pasaron a ser un marco de referencia para la sociedad que no sólo encontraba 
en la pequeña pantalla patrones de conducta en relación a las principales cuestiones de interés político; sino que también, consumiendo esos espacios de la programación, aprendía a emplear un nuevo lenguaje democrático que incluía vocablos carentes de contenido real durante la dictadura franquista. Este nuevo léxico, que en palabras de Santiago Guervós, "se convertirá sin duda en una de las principales armas para llegar a la consecución de la democracia" (1999: 14), se emplearía bajo las pautas de moderación propias del consenso que primó durante los primeros años de la Transición y que tanto influiría en las peculiaridades de estos espacios televisivos; de tal manera que el final del cambio consensuado supondría también el final de ese equilibrio monocolor que habría caracterizado los debates televisivos en líneas generales y promovería nuevos espacios con pautas de diálogo y tratamiento de contenido diferentes.

\section{Los debates de la Transición: clasificación y rasgos distintivos}

Los debates televisivos podemos incluirlos dentro del "hipergénero informativo" (Gordillo, 2009: 139) y, más concretamente, de los denominados géneros dialógicos o apelativos (Cebrián, 1992: 242); es decir, aquellos programas en los que se exponen opiniones diversas de forma dirigida, y en los que puede aparecer la polémica, en torno a un tema de actualidad, con un enfoque principalmente político y social (Bernaola et al, 2011: 156), sobre el que previamente se ha informado a la audiencia.

El programa de debate cuenta con la figura del moderador -miembro del equipo de la cadena televisiva- que cumple la función de controlar los tiempos y coordinar las intervenciones de los participantes; los cuales van cambiando según el tema a tratar y a partir de sus especializaciones y conocimientos.

Según Inmaculada Gordillo "la controversia resulta esencial en este género, pues sin ella el programa sería una tertulia" (2009: 13). Sin embargo, atendiéndonos a la clasificación de géneros que ha elaborado el Archivo de TVE para organizar sus propias emisiones $^{2}$, en este capítulo consideraremos debates todos aquellos espacios que se circunscriban a la definición expuesta en párrafos anteriores aunque no exista confrontación de opiniones; puesto que durante la Transición, y especialmente durante los primeros años, fue muy habitual que se debatiera con intervenciones coincidentes en opinión y sin que la polémica llegase a aparecer ante las cámaras aunque surgiesen tesis contrapuestas.

En este sentido, en muchas ocasiones, los debates televisivos de la Transición tomaron un cariz que hizo que recordasen más a una tertulia, por la falta de enfrentamiento, que a un debate. Así, la definición que aportan Martínez-Costa Pérez y Damas de tertulia bien podría referirse a los espacios de debates que se emitieron en TVE durante el cambio democrático: más que enfrentamiento dialéctico ofrecen al espectador

2 Como se ha expuesto en la introducción, la relación de programas de debate y su posterior selección para el visionado se han determinado a partir de la búsqueda del clasificador de género "Debate" en la Base de Datos del Archivo de TVE. Siguiendo el criterio de dicho archivo, no se ha hecho distinción entre coloquio, tertulia, mesa redonda o debate (Cebrián, 1992: 337-348) aunque, por otra parte, todos ellos se ajustan a la definición de la temática televisiva "Debate" que se defiende en este artículo. 
una acumulación o yuxtaposición de opiniones y no es habitual la defensa ferviente de cada postura (2008: 189-211). No obstante, los debates de la Transición se diferencian del concepto de tertulias más extendido en cuanto que los participantes no son invitados habituales y no predomina ni el lenguaje coloquial ni la espontaneidad en las intervenciones.

A lo largo de la Transición, y a medida que la democracia se iba implantando en el país, los programas de debate fueron evolucionando hacia un formato más dinámico en el que primaba la controversia frente a la "yuxtaposición de monólogos" (Imbert, 1990: 34) o los pseudo-debates de "entrevistas múltiples"3; y donde el espectáculo fue implantándose paulatinamente. En relación a ello, el perfil de los invitados también fue cambiando para dar opción a las ideologías o puntos de vista que durante años no tuvieron cabida en la pequeña pantalla.

Debido a la intensidad de los acontecimientos informativos durante los primeros años de la Transición, los temas que más interés despertaron fueron todos aquellos que estaban relacionados con la cambiante realidad política y la preocupante situación económica que atravesaba el país y que podía determinar el éxito o fracaso del proceso de democratización. Por ese motivo, los debates giraron habitualmente en torno a temas políticos o económicos desde una perspectiva estatal. Sin embargo, posteriormente, a la par que se estabilizaba la democracia, los espacios de coloquio empezaron a ampliar sus puntos de interés para centrarse así en cuestiones más genéricas y atemporales y a prestar una mayor atención a la política internacional.

El perfil más habitual de tertuliano era el de político, experto o periodistas. No obstante la voz de la calle y las "historias de vida" fueron haciéndose un hueco gradualmente en los programas de debate. Si bien es cierto que, aun cuando no se invitaba al plató a ciudadanos anónimos o no se dejaba intervenir al público o a los espectadores a través del teléfono, sí solía tenerse en cuenta la opinión de los ciudadanos a través de las referencias a encuestas o mediante la recogida de declaraciones en exteriores.

El moderador, salvo excepciones muy puntuales como en La Clave o, posteriormente, El Testigo (1981), no contaba con su propio turno ni solía introducir opiniones o debatir con los invitados. Era el responsable de marcar los tiempos del programa o de ir introduciendo los puntos a tratar a través, en la mayor parte de las ocasiones, de preguntas lanzadas al conjunto de los participantes o a alguno en particular.

La puesta en escena en forma de "U" fue la más habitual (Bernaola, 2011: 158-159) y los debates solían ser directos diferidos o grabaciones ( La Clave fue de los pocos que se emitía en directo). En cuanto a la estructura, fue muy habitual articular la escaleta del programa a partir de la proyección de un reportaje breve, un documental o una película que servía de percha para el debate posterior que se convertía en la parte esencial del programa.

3 Muchos de los programas que se emitieron durante la Transición se insertaban en la categoría de debates a pesar de ser realmente espacios de "entrevistas múltiples" en los que un grupo de periodistas o colaboradores puntuales, bajo la coordinación de un moderador, dialogaban sobre cuestiones de actualidad con un único invitado a partir de la fórmula pregunta-respuesta. 


\subsection{Principales programas de debate político}

En el mes de abril de 1975, TVE puso en marcha Sí o no, un programa de debate, presentado por Victoriano Fernández Asís que se emitió semanalmente por la Primera Cadena durante varios meses durante los últimos coletazos del franquismo. A lo largo de treinta minutos, se discutían temas de actualidad con el apoyo de reportajes breves y entrevistas y con la colaboración de unos invitados que, y de ahí el título del programa, tomaban postura a favor o en contra de la cuestión a debatir. Los puntos de vista de los tertulianos se contrastaban con las intervenciones del "asesor" (experto en la materia que se debatía) y el "informador" -un periodista que daba datos o analizaba la situación desde el punto de vista informativo- que ocupaban asiento en la misma mesa que el presentador.

El concepto de tertulia o discusión reducido a dos posturas enfrentadas -siempre dentro de un marco contenido y relativamente plural- volvió a influir en la puesta en marcha de un nuevo espacio de debate: Cara y Cruz. Dirigido y presentado por Enrique Meneses, con la colaboración de José Luis Orosa, Elisa Valero y Ricardo Ciudad, este programa comenzó a emitirse en mayo de 1976 los viernes a las 21.30 de la noche. Contaba con cuarenta y cinco minutos de duración y con una periodicidad quincenal.

Este debate se estructuraba en torno a tres elementos: una proyección de unos ocho minutos sobre un tema determinado, participación de dos o tres expertos sobre dicho tema desde el estudio y, en tercer lugar, un número de invitados, presentes en los centros regionales de TVE, que representaban al ciudadano español y que mantenían un coloquio con los expertos invitados en cada emisión desde los mismos centros regionales. Tras la introducción del tema sobre el que giraba el programa y la presentación de los invitados se proyectaba la filmación que representaba la "Cara" del debate. Tras esas imágenes, los expertos respondían a las preguntas formuladas por el conductor o por los invitados presentes en los centros regionales.

Este espacio no buscaba en ningún caso que los espectadores o los colaboradores de cada emisión llegaran a una tesis final inamovible al concluir el programa. Como su director declaró a la revista Tele Radio: "Nosotros lo único que queremos es exponer un tema pero no pidiendo alternativas para tomar una decisión. Por eso se llama Cara y Cruz. Y no Cara o Cruz. Lo que hacemos es ofrecer al espectador una serie de elementos, tratados por expertos y por gente de la calle. La conclusión dependerá del intelecto de cada uno en particular, de sus posibles ocurrencias sobre el mismo" (Tele Radio $\mathrm{n}^{\circ}$ 958, 3-9 de mayo de 1976: 18).

Al año siguiente no volvió a programarse. La causa de su eliminación de la parrilla pudo ser su espíritu polémico ${ }^{4}$. Fue un espacio muy controvertido que trató, por ejemplo, temas como el futuro del sindicalismo español, lo que permitió conocer el punto de vista de sindicalistas españoles o extranjeros y debatir sobre cómo pensaba la clase obrera española en 1976. La revista Tele-Radio llegó a escribir que se desconocía si este discutido espacio seguiría emitiéndose a pesar de tener ya grabados seis

4 A pesar del interés que encierra este programa, en los archivos de TVE sólo se conservan unos pocos fragmentos o bloques de dicho espacio sin que exista la posibilidad de poder visionar una emisión completa. 
debates de gran interés sobre asuntos como la huelga, el aborto y el divorcio (Tele Radio, $\mathrm{n}^{\circ}$ 977, 13-19 de septiembre de 1976: 49).

Sin embargo, si un debate de TVE estuvo vinculado a la polémica este fue, sin duda alguna, La Clave, que se ha convertido en un hito referencial de la televisión en España. Este programa empezó a emitirse en enero de 1976 durante el mandato de Gabriel Peña Aranda, el que fuera el primer director de RTVE nombrado tras el fallecimiento del Franco, y con Rafael Ramos Losada como director de la cadena pública (Munsó, 2001: 140). Dirigido y presentado por José Luis Balbín y con Adriano del Valle como realizador, este espacio nació de la adaptación del prestigioso programa francés Les Dossiers de L’Ecran (1967- 1991).

Durante su primera etapa, este controvertido debate se mantuvo en la parrilla ubicado en la noche de los viernes del Segundo Programa -como se conocía en aquel momento a la Segunda Cadena de TVE-, del 18 de enero de 1976 al 11 de abril de ese mismo año, para volver a reaparecer en color los sábados por la noche a finales de julio de 1977 y permanecer en antena hasta el mes de septiembre de 1980 (Tele Radio, ${ }^{\circ}$ 1023, 1- 7 de agosto de 1977: 18). La tercera etapa del espacio dirigido por Balbín llegó en abril de 1981 y concluye en enero de 1983 con un último programa dedicado a las inundaciones en el levante español (Ibáñez, 2006: 70-71).

La polémica estuvo presente en La Clave ya desde su primer día en pantalla para el que se escogió el tema del juego, que no estaba legalizado por aquel entonces. Es destacable que era un debate en directo; lo cual, y más aún teniendo en cuenta el contexto político de sus primeros años de emisión, le convertía en un espacio de la parrilla cuyos contenidos eran menos sencillos de controlar. Balbín hizo de este debate todo un símbolo de lo que representaba la apertura democrática y la libertad de expresión, hasta el extremo de que Pérez Ornia lo ha definido como el "baremo de los techos de libertad alcanzados durante la transición en TVE" (1988: 50).

Durante unas tres horas, La Clave debatía con expertos nacionales e internacionales sobre un tema de actualidad que se usaba como percha para la emisión de una película, relacionada con dicho tema, en torno a la cual se desarrollaba el intercambio de puntos de vista. Se estructuraba en tres partes diferenciadas: presentación, emisión de la película que ilustraba el coloquio posterior y, por último, el desarrollo del debate. En ocasiones se dejó también tiempo para las preguntas y reflexiones que el público podía proponer a través de llamadas telefónicas y que la voz del redactor-jefe, Javier Vázquez, planteaba posteriormente a los invitados. La puesta en escena era en forma de "U", en cuyo vértice se sentaba el director y moderador, Balbín, colocándose los invitados a ambos lados.

La Clave se distinguió del resto de los programas de debate no sólo por la fórmula de generar el coloquio a través del visionado de una película o por el mayor número de invitados provenientes de más allá de las fronteras españolas, sino también porque se trataba de un espacio que perseguía la polémica, la confrontación y el diálogo entre posturas encontradas. Al contrario que en la mayor parte de los espacios de debate de la parrilla de TVE durante la Transición, y sobre todo en los años del consenso, en $L a$ Clave no se recurría a rondas de preguntas y respuestas sin posibilidad de debate entre los invitados, ni el coloquio se terminaba reduciendo a una encadenación de monólo- 
gos, sino que los invitados exponían sus puntos de vista y argumentaban sus posturas cuando no había acuerdo entre los asistentes.

Si Balbín se convirtió en el paradigma de los programas de debate en tiempos de democratización, el espacio de España, hoy podría representar el mismo intento de ofrecer al espectador debate pero, al contrario de La Clave, desde una línea editorial que discurría paralela a la del Gobierno y donde las opiniones expuestas nunca llegaban a la controversia. Este espacio se puso en marcha con la llegada de Rafael Ansón Oliart a la dirección de RTVE en 1976. Dicha decisión, junto con la incorporación de otras novedades en la programación, buscaba renovar contenidos televisivos y que los espectadores notasen un cambio significativo en la cadena pública con respecto a lo que había sido la televisión franquista.

Bajo la dirección habitual de José Javaloyes y realizado por Luis Tomás Melgar, España, hoy comenzó su emisión en noviembre de 1976 durante el horario nocturno de prime-time, las diez de la noche, los miércoles en la Primera Cadena durante media hora y los domingos en la Segunda Cadena, ampliando el tiempo de emisión a una hora para poder profundizar y así satisfacer a un público más especializado (RTVE, 1977: 48).

El programa seguía un esquema que giraba alrededor de un tema normalmente relacionado con la actualidad política o económica acerca del cual se debatía con la colaboración de varios invitados relevantes, normalmente un número no superior a cuatro, provenientes del ámbito nacional político o académico en la mayor parte de las ocasiones. Para la puesta en marcha de España, hoy, Javaloyes contaba con el apoyo, como presentadores, de Fernando Ónega (colaborador del Gobierno presidido por Suárez) cuando se buscaba debatir cuestiones políticas, Horacio Sáenz Guerrero, si se trataba de cultura, y Diego Jalón para los debates sobre economía.

España, hoy -que presentaba ese esquema de "yuxtaposición de monólogos" al que ya hemos hecho referencia por ser característico de los espacios de opinión en la televisión de la Transición- desarrollaba el debate a partir de las respuestas que los invitados daban a las cuestiones formuladas por el presentador, tras la entradilla habitual de Javaloyes, encargado de introducir el tema a debatir con el apoyo, en la mayor parte de las ocasiones, de un reportaje breve que servía para enmarcar el comienzo de las intervenciones. Antes de cerrar la emisión, el presentador hacía un balance final de las principales conclusiones e ideas que habían surgido a lo largo del programa.

Recordando su colaboración en este debate como guionista y presentador, el periodista Fernando Ónega ha manifestado que en dicho espacio "nunca tuvo cabida el PSOE ni el PCE. El límite por la izquierda estuvo en Cantarero del Castillo (Reforma Social Española). Por eso no me atrevo a afirmar que hubiera pluralismo, pero en aquel momento era lo que se podía hacer. Sin embargo, espacios como este mostraron a los españoles que había una manera diferente de contrastar posiciones distintas y que la única vía para desmantelar el régimen anterior era la reforma frente a la ruptura" (Martín Jiménez, 2013: 95).

Las emisiones de España, hoy llevaron a los hogares de los espectadores el debate sobre los hitos que iban marcando el inicio de la Transición democrática buscando, como recuerda Onega, transmitir un espíritu del cambio pautado por el consenso y el diálogo frente a la ruptura y el enfrentamiento (Martín Jiménez, 2013: 95). 
Nacido también con un fuerte vínculo al proyecto gubernamental ${ }^{5}$, encontramos el programa Opinión Pública que se emitía en horario nocturno de la Primera Cadena y, al cabo de una temporada, de la Segunda Cadena (RTVE, 1978: 105). Para Manuel Palacio, este es uno de los programas a destacar dentro de la temporada 1976-77, "concebido por sus responsables como un espacio orientador respecto a cómo se establecía la opinión del país en temas como la democracia o la información política" (Palacio, 2001: 107).

Jana Escribano y Pedro Meyer presentaban este espacio de media hora en el que se recogía la opinión ciudadana a través de encuestas o de la formulación de preguntas a transeúntes a su paso por la calle y la de especialistas en un tema en concreto del ámbito de la actualidad nacional: el referéndum de 1976, las autonomías, los problemas de los españoles, la práctica deportiva en los más jóvenes, etc. Cada una de las cuestiones sobre las que versaban los estudios de opinión solía servir para desarrollar varias emisiones consecutivas. Tras la exposición de los resultados de esas encuestas a través de rótulos y el apoyo de una voz en off, se daba paso en el estudio a un debate con expertos sobre el tema alrededor del cual se había desarrollado la exposición. Lo cierto es que, aunque este espacio televisivo se ubicaba dentro de los programas informativos de debates, el debate como tal no llegaba a producirse puesto que las opiniones de los expertos se exponían de manera individual a partir de las preguntas que lanzaba el presentador y sin que hubiese ocasión de intercambiar puntos de vista entre los diferentes invitados que acudían al programa.

A finales de 1977 llegó a la Primera Cadena de Televisión Española el espacio semanal Cara a Cara, que se mantuvo en antena durante apenas un año. Dirigido y presentado por Federico Ysart, este debate de treinta minutos debía su nombre al hecho de que su esencia era el enfrentar ante las cámaras a dos invitados que defendían unas posturas claramente encontradas sobre un tema en concreto con el que tenían un fuerte vínculo, bien por ser expertos en él o por representar facciones políticas diferentes. Así, por ejemplo, en enero de 1978 -con la participación de Juan Rovira y Ciriaco de Vicente como representantes, respectivamente, de UCD y el PSOE- el debate se centró

5 Cuadernos para el diálogo relacionaba a Francisco Ansón, hermano del director general de RTVE en aquel momento, con la puesta en marcha del debate Opinión Pública: "Quizá lo más llamativo de la actuación de Rafael Ansón haya sido su nepotismo. Rápidamente coloca a su hermano Paco [Francisco] en un puesto clave, como es el de jefe del Servicio de Estudios de Contenido (censura), y a Luis María, hombre comprometido donde los hay con empresas periodísticas, le ofrece un programa idóneo para su lucimiento personal [La prensa en el debate]. [...] Pero también Francisco Ansón tiene sus negocios. Hay una empresa llamada IGT, dedicada a la investigación y estudios para que sean utilizados por los Telediarios. Esta empresa realiza encuestas -al decir de los técnicos- de dudoso rigor científico. Los datos que se dieron para el programa Opinión Pública (que trataba sobre la planificación familiar) fueron recogidos por teléfono. Sus resultados diferían radicalmente de los obtenidos por FOESSA o por el estudio realizado por Díez Nicolás sobre el tema. La compañía IGT parece que la controla, de una u otra manera, Paco Ansón. Lo evidencia la práctica de que cuanto a ella se refiere -encargos y entrega de resultados- se realiza a través de él" (Cuadernos para el diálogo, "El clan de los Ansón”, 5 de marzo de 1977: 44-45). 
en cómo la situación económica podía influir en la evolución de la Seguridad Social en España; mientras que en otra ocasión fueron el empresario Rodríguez Sahagún y el político y catedrático de economía Ramón Tamames quienes protagonizaron el coloquio acerca de los Pactos de la Moncloa.

A pesar de que la esencia del programa era el enfrentamiento dialéctico, la mayor parte de las veces, debido a ese espíritu de consenso que primaba en la televisión de los inicios de la Transición, el debate derivaba en un diálogo didáctico destinado a ilustrar a los espectadores sobre una cuestión de la actualidad política o económica. La emisión arrancaba con una entradilla del presentador que exponía el tema sobre el que se iba a debatir para después pasar a presentar a los dos invitados, que se encontraban sentados a ambos lados de Ysart (disposición en forma de "U") enfrente el uno del otro. El ritmo del programa lo marcaban las preguntas que iba lanzando el moderador a los invitados y que estos iban respondiendo con posibilidad de replicar la contestación del otro.

Como hemos visto en el caso de Ónega, su director y presentador, Federico Ysart, era un ejemplo de la imbricación existente durante la Transición entre los profesionales de TVE, los contenidos que se emitían en la cadena estatal y el ámbito político; puesto que, al mismo tiempo que dirigía espacios televisivos como Cara a Cara, Ysart trabajaba como asesor y subsecretario de UCD, el partido liderado por Adolfo Suárez, y era uno de los responsables de las campañas gubernamentales de los Pactos de la Moncloa y de la Constitución 6 .

Antes de terminar este apartado, habría que tener en cuenta que la situación política excepcional que se vivió en España durante la Transición llevó a que temáticas como la economía o la historia fueran tratadas en ocasiones desde el punto de vista de la actualidad política, traspasando así los límites temáticos en los que estaban inscritos algunos espacios de debate. Así, programas como Tribuna de la Historia (1978), Tribuna de la Economía (1978), o Más-Menos (1977), aunque su temática central era la historia y la economía, respectivamente, trataron temas de actualidad política desde una perspectiva retrospectiva o económica.

\section{Haciendo política en televisión. España, hoy ante el referéndum de la Ley para la Reforma Política}

Las metas planteadas por los dirigentes de la Transición durante los primeros meses del Gobierno de Suárez se concretaron en la Ley para la Reforma Política, diseñada por un equipo dirigido por Fernández Miranda. Esta "ley-puente", utilizando la ex-

\footnotetext{
${ }^{6}$ Ysart manifestaba su vinculación con el partido gubernamental como se refleja en estas declaraciones que hizo a la revista Tele-Radio: "En septiembre del año pasado [1977] el vicepresidente del Gobierno para asuntos políticos, Fernando Abril Martorell, me llamó para ser su asesor y desde entonces estoy trabajando con él. A finales de noviembre se estudió la posibilidad de hacer un programa de debate en TVE. La idea ofrecía bastantes riesgos por ser una fórmula inusual en nuestro medio. El programa ahí está. Creo que en Cara a Cara se da un contraste dialéctico entre fuerzas políticas o entre ideologías distintas con absoluta libertad, libertad que garantizan los mismos protagonistas del espacio". Tele-Radio, $\mathrm{n}^{\circ} 1052$, 20- 26 febrero 1978: 15.
} 
presión de Soto Carmona (1998: 37), fue aprobada mayoritariamente por las cortes franquistas en noviembre de 1976 y poco después fue respaldada en referéndum por la ciudadanía española. La entrada en vigor de esta ley supuso una profunda transformación política del Estado; puesto que establecía un sistema bicameral formado por Congreso y Senado, articulaba un régimen electoral y, entre otras medidas, garantizaba la puesta en marcha de una reforma legislativa.

Las semanas previas al referéndum, la cadena estatal, como un agente activo en el terreno de la comunicación política, introdujo en su parrilla habitual toda una serie de contenidos sobre la Ley de la Reforma Política y el referéndum a través de los cuales los españoles pudieran decidir si dar o no su apoyo al articulado. Bajo la astuta supervisión de su director general, Rafael Ansón, la pantalla televisiva fijó un triple objetivo: apostar por el proyecto reformista de Suárez, enfocarlo como si de un "tema-acontecimiento" se tratara (Berrocal, 2001: 39), informar a los espectadores acerca de la ley ante la que se posicionarían el 15 de diciembre con su voto y ofrecer en estas explicaciones toda una serie de "atajos cognitivos", es decir, claves que sirvieran para que la audiencia simplificara los contenidos de dicha reforma y acabara por verla como la única vía posible de transición (Popkin, 1990: 17).

Dentro de toda esa programación especial cabe destacar las emisiones del programa de debate España, hoy que prestó especial atención a dicha ley y a la postura que los ciudadanos debían tomar ante ella. Así este espacio emitió el 21 de noviembre de 1976 un debate sobre la cita con las urnas del 15 de diciembre, en el que participaron Gabriel Cisneros (Consejero Nacional, procurador en Cortes), Gabriel Elorriaga (Promotor de la Reforma Democrática en Madrid), Jesús Prados Arrarte (catedrático de Economía y miembro del Partido Socialista Democrático Español) y Luis Sánchez Agesta (catedrático de Derecho Político de la Universidad Complutense).

De los cuarenta minutos que duró el programa, sólo en la segunda mitad se desarrolló realmente el debate. En la primera parte, el espacio se centró en explicar a la audiencia mediante un breve reportaje, en qué consistía el referéndum que iba a celebrarse en diciembre. Esta labor didáctica-informativa quedó en manos del propio Ónega y de representantes políticos o personas implicadas en la organización de la votación. El primero en intervenir fue Eduardo Navarro Álvarez, vicesecretario general del Movimiento, que explicó el significado de la cita con las urnas del día 15. A continuación, Enrique Sánchez de León, director general de Política Interior, planteó las diferencias políticas y sociológicas entre este referéndum y el celebrado en 1966, durante la dictadura franquista -en el que se votó la Ley Orgánica del Estado- y manifestó los requisitos necesarios para que quedara garantizada la fiabilidad de los resultados. Tras sus palabras, Ignacio de Acha, se centró en el papel que tenía la Dirección General de correos y telecomunicaciones, bajo su supervisión, a la hora de transmitir y tratar por ordenador los datos relativos al recuento de las papeletas. Los dos últimos cortes versaron sobre el coste económico del referéndum y su comparativa con el caso italiano, explicación dada por Marcelo Ondania, corresponsal italiano en Madrid.

Dentro de este reportaje previo al debate destacó la línea continuista que se trazó desde el punto de vista histórico al insistir las distintas intervenciones en la comparativa del referéndum de 1966 con el que iba a celebrarse diez años después. Esa misma 
visión continuista, quedaba reflejada en las declaraciones de la gente de la calle a la que las cámaras de España, hoy preguntaron acerca de su opinión sobre la cita con las urnas y su intención de participar, y en cuyas respuestas fueron muchas las alusiones a aquella votación franquista, como si se tratara de un procedimiento afín al que iba a llevarse a cabo en diciembre. Sin embargo, la intervención de Ónega va a pretender marcar la diferencia entre uno y otro. En el de 1966, dijo el presentador "parecía que todos los españoles estábamos asombrosamente de acuerdo"; mientras que una década más tarde "la legalidad ya tiene oposición. Y oposición pública".

El valor intrínseco que el referéndum encerraba para España, hoy -y también para TVE- quedó manifestado en la intervención de José Javaloyes en la presentación del debate: el propósito de esa votación era "servir a la más compleja, ambiciosa y renovadora operación de ingeniería política intentada en nuestra historia constitucional. Rematar la construcción de un puente entre la orilla histórica del franquismo -de un régimen personalista- y la orilla de una democracia [...] es el pueblo español el que dirá, en definitiva, si pasamos o no pasamos el río".

Con el fin de proporcionar a la audiencia esos "atajos cognitivos", necesarios para que con facilidad pudiera posicionarse ante la ley y a ser posible posicionarse a favor de ella, los contenidos del articulado se simplificaron al máximo. Su aprobación se equiparó a la convocatoria de unas elecciones a cortes como se desprendía de la afirmación de Ónega -"Usted va a decidir con su voto si la próxima primavera tendremos unas elecciones libres para cubrir unas cortes que van a ser, supongo, constituyentes"- o como reflejaron las intervenciones de los invitados como Eduardo Navarro: "En este referéndum lo que se somete a la ratificación de la voluntad popular [...] es, ¿quieren los españoles elegir directamente a sus representantes en el parlamento a través de sufragio universal, igual, secreto y directo [...]?".

Tanto en el reportaje previo como durante el debate se insistió mucho en que la veracidad de los resultados estaba garantizada, puesto que el fantasma del pucherazo planeaba aún en el imago social. Las declaraciones del Director General de Correos y Telecomunicaciones, que explicó cómo se iban a gestionar los datos, sirvieron para reforzar la fiabilidad del recuento; mientras que, por otra parte, se dejaba de manos de los medios de comunicación la garantía última de la legalidad del referéndum, como si estos ya contaran en 1976 con un respaldo legal que les permitiera actuar como guardines de la democracia.

A pesar de que el mensaje que se emitía en este debate mostraba una clara sintonía con el gubernamental, parece que se trataba de lograr un equilibrio de fuerzas o al menos hacer llegar una voz un tanto disonante. Así, en la lista de invitados que participaron en el debate observamos una clara homogeneidad, puesto que se trataba de hombres vinculados, de una forma u otra, al centro-derecha. Sin embargo, entre todos ellos aparecía Jesús Prados Arrarte, al que se presentó a los espectadores como catedrático de Economía y miembro del Partido Socialista Democrático Español y, ante todo, como una prueba evidente de que en España ya tenían voz, en palabras de Fernando Ónega, "la generación del silencio, la clase política del silencio".

Este representante político de la izquierda será el único que ofrezca a lo largo del debate, que se inicia en la segunda mitad del programa, una visión realmente crítica 
de los contenidos de la ley; puesto que los otros tertulianos sólo habían expuesto pequeños matices contrarios al articulado, pero, en ningún caso, con intención alguna de generar polémica. Si bien Prados Arrarte no llegó a posicionarse en contra de la ley reformista, ofreció a los espectadores un análisis más profundo de sus contenidos, reprobando, por ejemplo, el papel que se otorgaba al Senado, la posibilidad que tenía el Rey de presentar una terna o el hecho de que ante unos contenidos tan complejos y variados todo quedara reducido a escoger entre un "Sí" y un "No".

Sin embargo, este programa, siguiendo el modelo de "yuxtaposición de monólogos", reducía el debate a las respuestas de los invitados a las preguntas que formulaba el presentador; con lo cual ni ante la intervención de Prados Arrarte ni ante ninguna otra se generó una discusión posterior, ni la opinión de unos fue respondida por otra contraria que matizara la expuesta anteriormente.

A la semana siguiente de esta emisión de España, hoy Javaloyes volvió a ofrecer al espectador un debate que buscaba exponer a la audiencia los aspectos clave de la ley y lo que iban a implicar los resultados de la votación; estableciendo como nexo de unión entre ambos coloquios la pregunta que Ónega formuló al término del primero de ellos: "Señores, ¿y después del Referéndum qué?". Si bien ese fue el punto final de aquella emisión, las cámaras continuaron grabando las contestaciones de los invitados; y dichas declaraciones fueron las empleadas para dar comienzo a este programa bajo el título La reforma política (28 de noviembre de 1976). Las respuestas ante la cuestión lanzada por el presentador no llegaron a plantearse qué sucedería si los votos negativos superaran a los positivos. Todos los contertulios expusieron cuál debía ser el siguiente paso, pero siempre partiendo del supuesto triunfo del "Sí" el 15 de diciembre. Constitución, elecciones o ambas cosas a la vez eran los próximos hitos que los invitados vaticinaban que habrían de acontecer en el país tras el escrutinio.

De los seis minutos que duraron las imágenes inéditas del anterior programa, lo más llamativo fue, en primer lugar, que se analizó la reforma como si ésta fuese un acto consumado ante el cual el pueblo se había decantado a favor. Como ejemplo de esta visión concluida del cambio encontramos las palabras con las que el director del programa dio comienzo a la emisión: "El puente está hecho. La reforma aprobada. Con los mismos materiales y los propios hombres de que Franco se sirvió se ha construido el arco que salva el vacío de poder y enlaza con la otra orilla de la Transición".

En segundo lugar, llama la atención cómo al hablar de lo que habría de acontecer tras la cita con las urnas no se solía hacer mención a la elaboración de una constitución, sino a la reforma de la ya existente; como si la legalidad franquista y la democrática fueran equivalentes a falta sólo de pequeños retoques. Con lo cual se estaba generando una imagen de paso de una legalidad a otra; igual de válidas las dos desde el punto de vista democrático, aunque cada una representara una respuesta diferente ante circunstancias históricas dispares. Esas circunstancias, y sólo ellas, eran, según estas argumentaciones, las responsables de que hubieran cambiado las necesidades del país, y no el que uno de esos sistemas fuera más deseable que el otro. Sin embargo, a pesar de que se insistía mucho en la idea de continuismo reformista, también se recalcaron las mutaciones que había experimentado el país; así Ónega al abrir la emisión llegó a afirmar: "Como diría un castizo; esta no es mi política, que me la han cambiado". 
El contenido didáctico del programa superaba al dedicado al debate propiamente dicho; hasta el punto de que los invitados se quejaban de no poder intercambiar opiniones con los allí presentes. Así pues, el objetivo principal de esta emisión no era cotejar puntos de vista dispares sino explicar a los telespectadores en qué consistía la ley.

España, hoy siguió centrando su mirada en el referéndum tanto antes como después de su celebración. El 1 de diciembre los espectadores pudieron asistir al coloquio España ante las urnas en el que se trataron cuestiones relacionadas con los trámites relativos al día de la votación. El programa recurrió a un esquema de contenidos muy semejante al titulado El Referéndum; así también se buscó como referente lo ocurrido en otros países, se intentó convencer a la audiencia de que la credibilidad de los resultados estaba garantizada a pesar del temido "vicio del pucherazo" y se resumió la esencia de la cita con las urnas en "decir Sí o decir No a que los ciudadanos podamos elegir libremente nuestros representantes".

La originalidad de este espacio con respecto a los anteriores residió en que los invitados -Julio Alcaide Inchausti (estadista), Juan Díaz Nicolás (director del Instituto de Opinión Pública), Sánchez de León (director general de Política Interior), Ignacio Acha y Sánchez Arjona (director general de Correos y Telecomunicaciones) y Eduardo Navarro Álvarez (vicesecretario general del Movimiento) - fueron respondiendo a las dudas que personas de la calle habían planteado ante las cámaras de televisión. Con lo cual, volvemos a ver cómo se transcendía la naturaleza propia de un coloquio para convertir el programa en una emisión puramente ilustrativa del procedimiento del voto del referéndum y los requisitos necesarios para que éste fuera válido.

Una semana después Javaloyes dirigió otro monográfico, en esta ocasión bajo el título Días antes del referéndum. Ónega presentó a los invitados recordando que "huele a urnas" y que los pasquines, las pintadas recuerdan que "ya estamos en la gran recta final". Uno de esos grafitis a los que se hizo alusión sirvió para lanzar la primera pregunta a los tertulianos: “¿Franco hubiera votado No?”. Sin embargo, aunque varios de los invitados pretendieron generar polémica buscando la reacción de los contertulios a sus respuestas, de nuevo, el formato del programa impidió la confrontación.

\section{Conclusiones}

Durante la etapa de Transición de la dictadura franquista a la democracia, los dirigentes del cambio político confiaron en que la pequeña pantalla podía influir de manera importante en la sociedad al servir de instrumento de socialización a través de la interpretación que hacía de la realidad y del sentimiento de participación y compromiso socio-político que trasmitía a la audiencia. Partiendo de esta premisa, Televisión Española, guiada por el Gobierno, trató de servir de canal de orientación de cara a las transformaciones que necesitaba la ciudadanía, sensibilizando a la población sobre los principios que traía consigo el nuevo sistema político e intentando contribuir a la formación de una sociedad más democrática y pluralista. De esta manera, la cadena estatal colaboró en la tarea de servir a la consolidación de unos valores y una cultura democráticos, reforzando unos principios sobre otros y apoyando un proyecto muy concreto de cambio político.

Como parte del modelo de televisión pública que primó en la Transición, TVE puso en marcha toda una serie de espacios de debate político que perseguían proyec- 
tar a la audiencia una imagen de pluralismo y libertad de expresión aún cuando esta no estaba regulada por la ley. Los temas que en estos debates se trataban y la manera de tratarlos, como hemos podido ver en el caso concreto de España, hoy, transmitieron una imagen moderada y abierta al diálogo tanto de la política como de la Transición en general. Estos programas, como si fuesen una representación ideal de un parlamento, actuaron como todo un símbolo de la democratización que vivió España a finales de los setenta y como tal evolucionó a la par reflejando unas pautas de comportamiento que buscaban ser idénticas a las que proyectaban los principales dirigentes del cambio y construyendo unos contenidos donde continuismo y ruptura estaban equilibrados, del mismo modo que lo estuvieron en el plano político; de tal manera que el espectador podía llegar a trazar una correspondencia entre la realidad televisiva y una realidad política moderada, plural y democratizadora.

Los distintos proyectos de programas de debate político que se pusieron en marcha - pocos de ellos con una duración que se prolongara más de una temporada - ejercieron también una labor docente e informativa al hacer llegar a la sociedad mensajes formativos que ayudaron a paliar la deficiencia en cultura democrática que existía en el país. Al mismo tiempo, el público pudo ir aprendiendo un nuevo lenguaje democrático que incluía términos carentes de contenido real durante el franquismo como tolerancia, entendimiento, concordia, convivencia; mientras que se evitaban otros términos como ruptura o revolución que no representaban el espíritu del proyecto de Transición en sus inicios.

Como se ha querido mostrar en este artículo, esa actitud dialogante y consensuada que primó en los programas de debate emitidos por TVE durante los años del consenso (1976-1979) se pudo llevar a cabo, principalmente, por la habitual ideología monocolor de sus invitados y la frecuente ausencia de confrontación que seguía a las palabras del tertuliano, en el caso de que lo hubiera, que no concordaba con las opiniones del resto de los allí presentes. Frente a estos espacios, convertidos en una serie de "yuxtaposiciones de monólogos", encontramos el programa La Clave, uno de los ejemplos más relevantes de lo que podríamos denominar el "lavado de cara del sistema"; es decir, todas aquellas excepciones en la tónica más habitual de la parrilla televisiva que servían para equilibrar la balanza en el cambio reformista que se llevó a cabo en los contenidos de la cadena pública.

Desde los inicios de la Transición, Televisión Española tomó conciencia de su capacidad de influencia y del papel de líder de opinión que estaba destinado a jugar en aquel delicado momento histórico. Esta posibilidad que se le presentaba de ser vehículo de una visión del cambio acorde con la marcada por los dirigentes, quedó reforzada al tener TVE el monopolio en ese ámbito mediático. Con lo cual, los debates sobre actualidad política se proyectaron como si fuesen un canal informativo de gran alcance y un posible conformador de la opinión del amplio sector de la población al que se dirigía a diario la televisión.

\section{Referencias}

BENEDICTO MILLÁN, Jorge: "Sistemas de valores y pautas de cultura popular predominantes en la sociedad española (1976-1985)" en TEZANOS, José Félix, CO- 
TARELO, Ramón y DE BLAS, Andrés (eds.): La Transición democrática española. Madrid, Sistema.

BERNAOLA, Itziar et al. (2011): Programas informativos y de opinión en televisión. Producción y realización. Madrid, Editorial Síntesis.

BERROCAL, Salomé (2001): Comunicación política y televisión. Definición de un marco teórico en la investigación electoral en televisión. Las elecciones legislativas de 1993. Tesis doctoral. Madrid, Universidad Complutense.

CEBRIÁN HERREROS, Mariano (1992): Géneros informativos audiovisuales. Madrid, Editorial Ciencia.

GORDILLO, Inmaculada (2009): Manual de narrativa televisiva. Madrid, Editorial Síntesis.

IBÁÑEZ, Juan Carlos (2006): "La Clave” en PALACIO, Manuel (ed.): Las cosas que hemos visto. 50 años y más de TVE. Madrid, Instituto RTVE, Madrid, 2006, pp. 7071.

IMBERT, Gerard (1990): Los discursos del cambio. Imágenes e imaginarios sociales en la España de la transición (1976-1982). Madrid, Akal.

JULIÁ, Santos et al. (coord., 1996): Memoria de la transición. Madrid, Taurus.

MARTÍN JIMÉNEZ, Virginia (2013): Televisión Española y la Transición democrática: La comunicación politica del Cambio (1976-1979). Valladolid, Ediciones Universidad de Valladolid.

MARTÍNEZ-COSTA PÉREZ, Ma Pilar y HERRERA DAMAS, Susana (2008): "La tertulia radiofónica como un tipo de conversación coloquial". Doxa Comunicación, $\mathrm{n}^{\circ}$ 5. Madrid, pp. 189-211.

MORODO, Raúl (1993): La transición política. Madrid, Tecnos.

MUNSÓ CABÚS, Juan (2001): La otra cara de la televisión. 45 años de historia y política audiovisual. Flor del Viento.

PALACIO, Manuel (2001): Historia de la televisión en España. Barcelona, Gedisa.

PÉREZ ORNIA, José Ramón (1988): La televisión y los socialistas. Actividades del PSOE respecto a la televisión durante la transición (1976-1981). Madrid, Editorial de la Universidad Complutense.

POPKIN, Samuel (1990): "Information Shortcuts and the Reasoning Voter" en GROFFMAN, B. (ed.): Information, participation and choice. An economic theory of democracy. Ann Arbor, The University of Michigan Press, pp. 17-35.

PREGO, Victoria (1995): Así se hizo la Transición. Barcelona, Plaza \& Janés.

RTVE (1977): Anuario 1976. Madrid, RTVE.

RTVE (1978): Informe 1978. Madrid, RTVE.

SANTIAGO GUERVÓS, Javier de (1999): El léxico político de la Transición española. Salamanca, Universidad de Salamanca. 
TUSELL, Javier (1999): La transición española a la democracia. Madrid, Historia 16. SARTORIUS, Nicolás y SABIO, Alberto (2007): El final de la dictadura. La conquista de la democracia en España noviembre de 1975- junio de 1977. Madrid, Temas de Hoy.

SOTO CARMONA, Antonio (1998): La transición a la democracia. España, 19751982. Madrid, Alianza. 